\title{
Climate change and infectious diseases
}

\section{Adam Craig ${ }^{\mathrm{A}}$, Gillian Hall ${ }^{\mathrm{B}}$ and Richard Russell ${ }^{\mathrm{C}}$}

ANSW Health Public Health Officer Training Program, NSW Department of Health

BNational Centre for Epidemiology and Research, Australian National University

CDirector, Department of Medical Entomology, University of Sydney and Institute of Clinical Pathology and Medical Research (ICPMR)

It is now widely accepted that the earth's climate is changing as a result of the accumulation of greenhouse gases in the atmosphere. Climate change is in turn causing environmental and ecological changes that have, and will increasingly, influence human health.

Australia's continental-average temperature has risen by $0.7^{\circ} \mathrm{C}$ from 1910 to 1999 , with most of this increase occurring since $1950 .{ }^{1}$ Recently, the United Nations Intergovernmental Panel on Climate Change predicted that under a continued high greenhouse gas emissions scenario global mean temperatures could rise by $6.4^{\circ} \mathrm{C}$ (range $2.4^{\circ} \mathrm{C}$ to $6.4^{\circ} \mathrm{C}$ ) by 2099 ; under a low emission scenario temperatures are expected to rise between $1.1^{\circ} \mathrm{C}$ and $2.9^{\circ} \mathrm{C}$ over the same period. ${ }^{2}$

The World Health Organization estimates that the global burden of climate change is 150000 deaths $(0.3 \%$ of global mortality) and 5.5 million disability-adjusted life years $\left(0.4 \%\right.$ of the global total) per year. ${ }^{3}$ This burden is not borne evenly across the globe, with poorer, less adaptable communities at lower latitudes carrying significantly larger burdens. ${ }^{4}$

When estimating or modelling the health impacts of climate change, there are many uncertainties due to inconsistencies and gaps in global knowledge about climate variability, lack of reliable data across populations, poor applicability of global models to local scenarios and incomplete (yet growing) understanding of the climate-health relationship, ${ }^{3}$ particularly related to human adaptability to the effects of climate change. These issues, coupled with a delay between the causes of climate change and the effects, mean that models should be interpreted as a guide rather than an exact predication of the future impact.

Globally, climate change will have major impacts on health by influencing temperature-related illness, malnutrition, diarrhoeal disease, injury, malaria and other vector-borne diseases. ${ }^{3}$ The influence that climate change will have on each of these causes of ill-health will not be distributed evenly. For example the relative risk of death due to malnutrition in parts of South-East Asia is predicted to be as high as 1.33 by 2030 while remaining unchanged in Australia. ${ }^{3}$

The impact climate change is likely to have on health in NSW will primarily be related to more frequent, intense and longer periods of high temperature, predominantly in the central-western areas of the state, ${ }^{1}$ causing heat stress and exacerbating sensitive cardiac and respiratory medical conditions. More frequent and intense storm activity will also increase the risk of injury. ${ }^{5,8}$

Malaria and dengue 'receptive zones' may extend southward in northern Australia; however, there is little evidence to suggest that increases in infection predicted for other parts of the world will occur in NSW due to environmental, vector and health service dynamics. ${ }^{6,7} \mathrm{NSW}$ may, however, experience an increase in imported vector-borne diseases due to increased incidence in other regions. ${ }^{6,8}$

There is evidence to suggest a link between climate change and microbial food-borne disease, with a positive correlation between seasonal and latitudinal temperature variability and the amount of food-borne and diarrhoeal illnesses observed. It is likely that climate change will cause an increase in food-borne disease notifications; however, caution is required in inferring a direct link due to the multiple and complex confounding factors. Changing climate may also influence human exposure to natural and man-made toxins such as risk of exposure to blue-green algal blooms. ${ }^{9}$

It has been hypothesised that there will be indirect social, economic and/or political impacts from climate change that will impact on health, such as regional civil unrest, economic disturbances or population migration. ${ }^{6}$

The significance climate change will have on public health practice in NSW will vary depending on geographic area and the ability of populations to adapt to any increased risks posed.

\section{References}

1. Hennessy K, Page C, McInnes K, Jones R et al. Climate Change in New South Wales. CSIRO, Division of Atmospheric Research Climate Impact Group, 2001.

2. United Nations Intergovernmental Panel on Climate Change. The Fourth Assessment Report of the United Nations Intergovernmental Panel on Climate Change: Climate Change 2007: The Physical Science Basis. UNIPCC, 2007. 
3. World Health Organization. The World Health Report 2002. Geneva: World Health Organization, 2002.

4. McMichael AJ, Campbell-Lendrum D, Kovats S, Edwards S. et al. Chapter 20: Global Climate Change in Comparative Quantification of Health Risk. Geneva: World Health Organization. At http://www.who.int/publications/cra/ chapters/volume2/1543-1650.pdf, accessed 2 December 2006.

5. NSW Greenhouse Office. Climate change in NSW-Part 2: Projected changes in climate extremes. NSW Greenhouse Officer. At http://www.greenhouse.nsw.gov.au/_data/ assets/pdf_file/3530/Climate_Change_NSW_Part2_summary. pdf, accessed 22 April 2007.

6. Commonwealth Department of Health and Ageing. Human Health and Climate Change in Oceania: A Risk Assessment 2002. Canberra: Commonwealth Department of Health and Ageing, 2002.
7. Russell RC. Mosquito-borne arboviruses in Australia: the current scene and implications of climate change for human health. Int J Parasitol 1998; 28: 955-69. doi:10.1016/S00207519(98)00053-8

8. United Nations Intergovernmental Panel on Climate Change. Climate Change 2007: Impacts, Assessment and Vulnerability, Working Group II Contribution to the Intergovernmental Panel on Climate Change 4th Assessment Report, Summary for Policy Makers. New York: World Meteorological Office/United Nations Development Program, 2007. At http://www.ipcc.ch/SPM13apr07.pdf, accessed 24 April 2007.

9. Hall G, D'Souza R, Kirk M. Foodborne disease and the new millenium: out of the frying pan and into the fire. Med J Aust 2002; 177: 614-618.

\section{NSW Public Health Bulletin Subscription Form and Electronic Early Alert Service}

To subscribe to the hard copy of the NSW Public Health Bulletin or to change your subscription details please complete this form and return it by email (phbulletin@doh.health.nsw.gov.au) or fax (61 29391 9232).

The Bulletin can be accessed electronically from www.publish.csiro.au/journals/phb. Subscribe to the Early Alert service to be notified as soon as it appears online (http://publish.csiro.au/nid/226.htm?nid=25\&aid=685).

\section{Subscription information}

$\square$ I wish to receive the NSW Public Health Bulletin:

My details are as follows

Name:

Organisation:

Mailing Address:

State: Postcode: Country:

Telephone: Facsimile:

Email:

\section{Change of Address}

I wish to change my mailing details, as follows:

Name:

From: [Insert old address]

To: [Insert new address] 